\title{
Decreasing pore formation in multiple-sheet laser joining with interfacial polymeric contaminations
}

\author{
Peer Woizeschke $^{1}$ - Eugen Mosgowoi ${ }^{2} \cdot$ Frank Vollertsen $^{1,2}$
}

Received: 29 August 2014 / Accepted: 15 April 2015 / Published online: 8 May 2015

(C) The Author(s) 2015. This article is published with open access at Springerlink.com

\begin{abstract}
Deep-penetration laser welding is an efficient joining technology for overlap joints nowadays. However, contaminations usually having a lower vaporization temperature can cause seam defects like pores and melt ejections during the process. Many approaches have been investigated, e.g., for the industrially interesting case of welding zinc-coated steel sheets. Suitable techniques for sufficient reduction or avoidance of porosity require additional process steps or timeconsuming preparations. In this paper, three-sheet joints having polymeric interlayers as exemplary extensive contaminations are investigated. Seams feature extreme porosity after standard single-pass welding. The porosity can be decreased significantly when repeating the welding process (double-pass welding). This effect on formation of porosity is modified in this paper. Instead of two processes, longitudinal beam oscillation is applied. The center porosity in longitudinal sections, used as indicator for the porosity of seams, can be reduced significantly from more than 50 to $20 \%$ by using the beam oscillation technique. As the main reason, the increased degassing time due to the lengthening of the melt pool depending on oscillation parameters is identified. Simultaneously, the results indicate that the seam width must not increase similarly to avoid that further evaporation of contamination material cancels out the achieved benefit by lengthening.
\end{abstract}

Doc. IIW-2556, recommended for publication by Commission IV "Power Beam Processes".

Peer Woizeschke

Woizeschke@bias.de

1 BIAS - Bremer Institut für angewandte Strahltechnik $\mathrm{GmbH}$, Bremen, Germany

2 University of Bremen, Bremen, Germany
Keywords (IIW Thesaurus) Laser welding · Impurities · Porosity

\section{Introduction}

An increasing number of manufacturers choose laser welding technologies in assembling due to their abundant advantages [1] like reduction of cycle times, high potential for automation, and high process efficiency [2]. Thereby, two different welding modes can be distinguished: deep-penetration and heat-conduction laser welding. Deep-penetration welding is characterized by the formation of a keyhole, a vapor-filled capillary existing during the process. A keyhole is generated if the energy density exceeds the critical value for vaporization of the specimen material. Deep-penetration welding enables seam cross-sections with high aspect ratios, depending on the process parameters [3], which results in a low heat input and therefore leads to less distortion compared to other welding techniques in the macro as well in the micro range. Deeppenetration welding is an efficient technique suitable for welding overlap or multiple-sheet joints at high welding speeds in industrial applications [4]. However, residues or interlayers of coatings, impurities, or other contaminations can occur between overlapping sheets. This additional material can be critical for joining processes due to a high risk of seam defects like pore formation and melt ejections caused by its vaporization. Contaminations can be unwanted residues of previous fabrication processes like oil, dirt, varnish, and lubricants or wanted coatings and interlayers. Zinc coatings, for example, are typically used as protection against corrosion on galvanized steel sheets [5]. Polymeric interlayers, for example, are applied as hybrid metal-polymer-laminates for vibration damping [6]. In addition, hybrid metal-polymer-laminates are under investigation as transition structure for 
aluminum-CFRP (carbon fiber-reinforced plastic) joining [7]. Thereby, the hybrid laminate merge into a pure metal laminate. The risk of partial existence of polymeric residues within this metal laminate requires a previous seal welding [7].

In case of metallic joints, such contaminations usually have lower vaporization temperatures than the base material [8]. The contaminations vaporize due to heat conduction ahead of the process before the liquid melt pool arrives. Thus, the vapor pressure of the gaseous contamination between the sheets increases leading to uncontrolled degassing through the melt pool [8]. Geiger et al. describe two failure generating mechanisms in welding of oil-contaminated steel sheets: (1) keyhole collapses can cause pores and spillings along the weld seam and (2) melt ejections can be initiated by melt pool waves which are caused by the evaporating contaminations. Avoiding pores, spatters, and blow holes due to melt ejections has been one of the main challenges in welding zinc-coated steel sheets for many years [9]. Several research projects have dealt with approaches to realize defect-free weld seams using high-power $\mathrm{CO}_{2}$ or $\mathrm{Nd}-\mathrm{YAG}$ laser sources. In case of zero-gap joints, the degassing can only be realized through the melt pool or the keyhole [10]. Thus, the keyhole diameter and stability on the one hand and the melt pool size on the other hand affect the porosity of seams. Therefore, the time available for the vaporized contaminations to escape from the melt pool has to be enlarged to decrease the porosity. Approaches like elongating the laser beam [11], using pulsed laser processes [12], using laser power modulation [13], creating vent holes in the bottom sheet [14], using different shielding conditions [15], using a second laser beam [5], splitting a laser beam into two beams [16], using rotating beam [4], or applying beam oscillation [17] have been developed and investigated for welding of zinc-coated steel sheets. Berend et al. have investigated the mentioned application of an oscillating laser beam in order to reduce pore formation in overlap welding of aluminum as well as zinc-coated steel sheets [17]. It has been shown that pore formation decreases compared to welding without oscillation at high oscillation frequencies of 1000 and $1500 \mathrm{~Hz}$ in case of the aluminum joints. However, no effect was measured for the joints of zinc-coated steel using the same setup. The most promising solution for welding zinc-coated steel sheets is to adjust defined gaps between the overlapping sheets by spacers [18], humps [19] or dimples [20] in order to enable controlled lateral degassing of the vaporized zinc. In addition to single-pass strategies, Ma et al. analyzed a two-pass welding approach in zero-gap configuration. It was found that two-pass welding can avoid the pore formation successfully in overlap welding of zinc-coated galvanized steel sheets. A defocused laser beam has been used for preheating. Afterwards, partial penetration welding was carried out by using a focused laser beam [21]. The main disadvantage of that strategy is the additional process step of preheating and as a result the extension of the process time.

In this paper, deep-penetration welding of multiple-sheet joints with polymeric interlayers is investigated. The polymeric interlayers represent an extreme case of contaminations in the interspaces of overlapping sheets. Standard weld seams of equal multiple-sheet specimens without any polymeric material between the sheets show no pores or other seam defects; see Fig. 1a. In contrast, specimens welded with polymeric interlayers show open pores all over the seam as shown in Fig. 1b. However, a significant increase of the seam quality was observed after a second welding pass (Fig. 1c). The magnification of the seam surface in Fig. 1d demonstrates that the visible line in the center of the seams, shown in Fig. 1a, c, does not represent a crack. This is confirmed by the cross-section shown in Fig. 1e, which belongs to the seam in Fig. 1a. Thus, it is probably an optical artifact due to the incident of light under the microscope.

The double-pass welding using equal process parameters in both passes decreases the porosity of such seams significantly. In order to avoid the need of a second welding process, the application of beam oscillation is investigated. The idea of the paper bases on the hypothesis that the seam quality can be significantly increased by longitudinal beam oscillation (parallel to the welding direction). Thus, decreasing the welding speed or applying additional process steps in the form of welding the seam twice can be avoided. In addition, no special preparations of the joint like adjusting defined gaps or other mentioned approaches are necessary.

\section{Experimental}

\subsection{Materials}

Multiple-sheet specimens are investigated consisting of three stainless steel foils having polymeric contaminations in the interspaces. The chemical composition of the used stainless steel 1.4301 according to EN 10088-2:2005 (AISI 304) is given in Table 1 . As polymer contamination, the premixed thermoset epoxy resin HexFlow RTM6 by Hexcel is used. Main components of RTM6 are tetraglycidyl methylene dianiline, 2,6-diethylaniline, and 2-isopropyl-6-methylaniline [22]. The test specimens were manufactured using $20-\mu \mathrm{m}$ thick and 13-mm-wide spacers positioned along all edges in the two interspaces between the three steel foils having a thickness of $0.25 \mathrm{~mm}$ each. The resin filled in the interspaces of the multiple-sheet laminate was cured at a temperature of $120^{\circ} \mathrm{C}$ for $6 \mathrm{~h}$ being compressed by $3 \mathrm{~N} / \mathrm{mm}^{2}$. Afterwards, the metal surfaces of the specimens were cleaned manually by 
Fig. 1 Seam surfaces of three-sheet stainless steel overlap joints: a single-pass welding of a specimen without any contaminations in the interspaces; b single-pass welding in case of existing polymeric interlayers; c double-pass welding in case of existing polymeric interlayers; $\mathbf{d}$ magnification of the visible center line on the seam surfaces; $\mathbf{e}$ cross-section of the single-pass welded seam without any contaminations shown in Fig. 1a
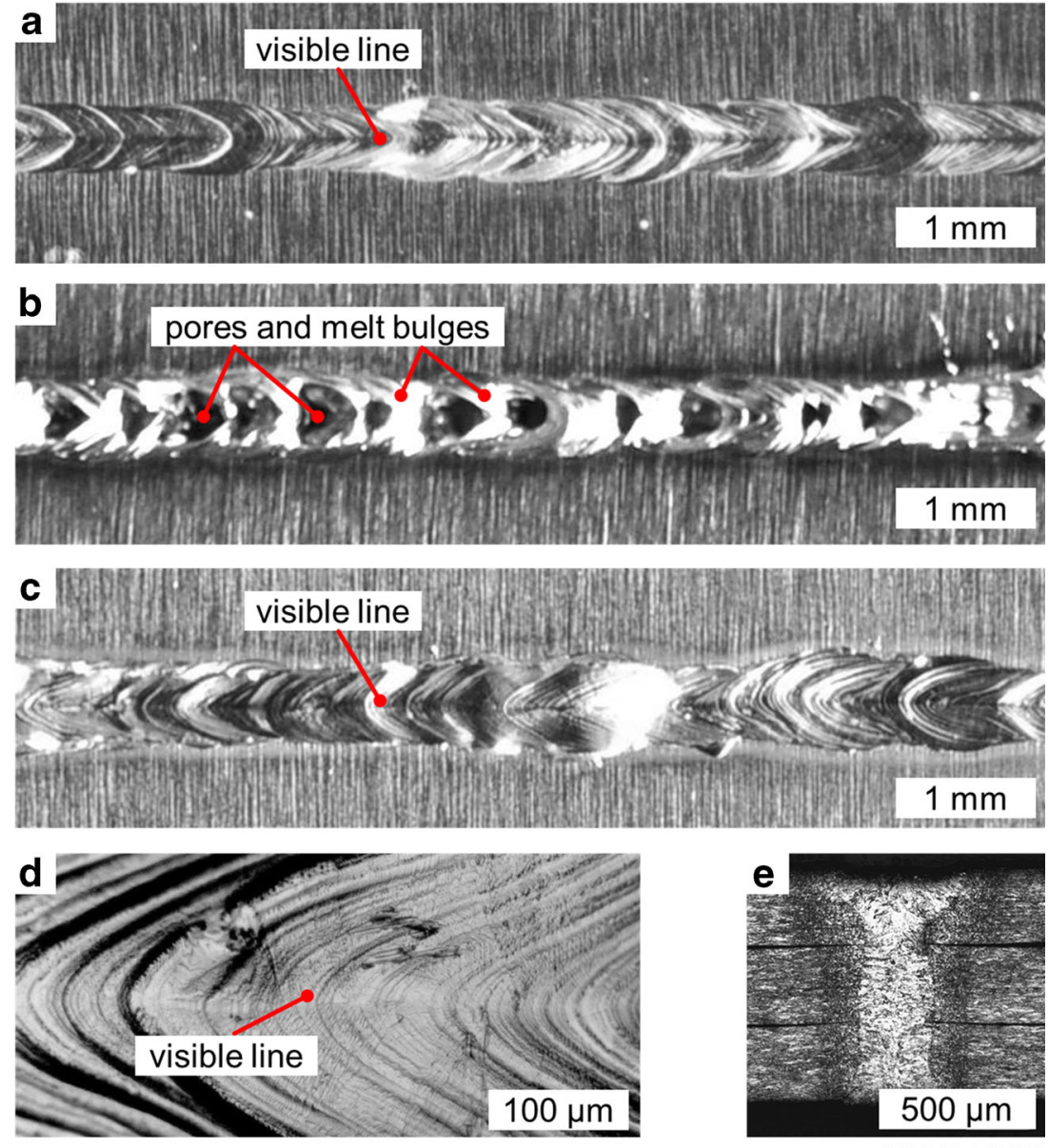

BIAS ID 141674 ethanol before welding. Welds of $70 \mathrm{~mm}$ length were carried out in length intervals of $10 \mathrm{~mm}$.

\subsection{Experimental setup}

\subsubsection{Welding setup}

The principle of the welding setup is schematically presented in Fig. 2. The laser head is equipped with a scanner system (DC-Scanner, ILV) to enable longitudinal oscillations of the laser beam parallel to the welding direction. The oscillation is realized by a rotating mirror.

The beam oscillation is characterized by three parameters: oscillation width, oscillation frequency, and oscillation mode. The resulting laser path for an exemplary sinusoidal beam oscillation with an oscillation width of $0.9 \mathrm{~mm}$ and an oscillation frequency of $100 \mathrm{~Hz}$ at a welding speed of $50 \mathrm{~mm} / \mathrm{s}$ is demonstrated in Fig. 3. In this paper, only the sinusoidal oscillation mode is used. It is illustrated that a seam position can be passed several times by the laser spot depending on oscillation width $\Delta l_{\text {osc }}$, oscillation frequency $f_{\text {osc }}$, and

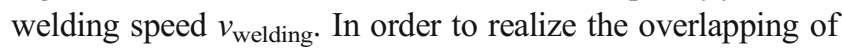
successive laser passes along the complete seam, the seam progress per oscillation period $\Delta l_{\text {period }}$ (see Fig. 3) has to be smaller than half of the laser progress $\Delta l_{\text {forward }}$ during the second half of the oscillation period (Eq. 1). The seam progress per oscillation period $\Delta l_{\text {period }}$ is calculated by the quotient of welding speed and oscillation frequency (Eq. 2). The progress $\Delta l_{\text {forward }}$ is given by dividing the sum of laser speed $v_{\text {laser }}$ and welding speed by the double oscillation frequency (Eq. 3). As result, laser speed has to be at least three times faster than the welding speed (see Eq. 4) to fulfill the requirement for

Table 1 Chemical composition of the used stainless steel 1.4301 according to EN 10088-2:2005 [25]

\begin{tabular}{lllllllll}
\hline Steel & \multicolumn{1}{l}{ Chemical composition (wt.\%) } & & & & \\
& \cline { 2 - 8 } & $\mathrm{C}$ & $\mathrm{Si}$ & $\mathrm{Mn}$ & $\mathrm{P}$ & $\mathrm{S}$ & $\mathrm{Cr}$ & $\mathrm{Ni}$ \\
\hline 1.4301 & $\leq 0.07$ & $\leq 1.00$ & $\leq 2.00$ & $\leq 0.05$ & $\leq 0.02$ & $17.5-19.5$ & $8.0-10.5$ & $\leq 0.11$ \\
\hline
\end{tabular}




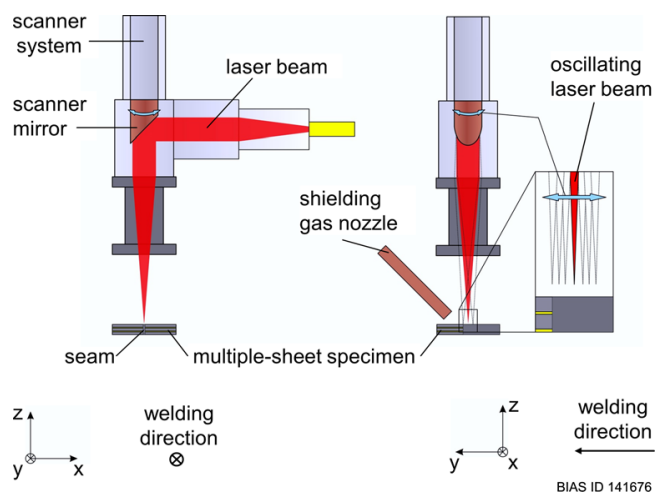

Fig. 2 Principle of the welding setup

overlapping laser passes at each seam position. Laser speed is calculated by the product of oscillation frequency and the double-oscillation width according to Eq. 5. In consequence, the oscillation frequency has to be higher than the quotient of welding speed and oscillation width multiplied by a factor of $3 / 2$ (see Eq. 6) to provide that each seam position is passed at least two times by the laser beam.

$\Delta l_{\text {period }} \leq \frac{1}{2} \cdot \Delta l_{\text {forward }}$

with $\Delta l_{\text {period }}=\frac{v_{\text {welding }}}{f_{\text {osc }}}$

and $\Delta l_{\text {forward }}=\frac{v_{\text {laser }}+v_{\text {welding }}}{2 f_{\text {osc }}}$

$v_{\text {welding }} \leq \frac{v_{\text {laser }}}{3}$

with $v_{\text {laser }}=f_{\mathrm{osc}} \cdot \Delta l_{\mathrm{osc}} \cdot 2$

$f_{\text {osc }} \geq \frac{3}{2} \cdot \frac{v_{\text {welding }}}{\Delta l_{\text {osc }}}$

A single-mode fiber laser with a wave length of $1070 \mathrm{~nm}$ and the maximal output power of $1 \mathrm{~kW}$ has been used (YLR-1000-SM-CW, IPG) guided in an optical fiber with a core diameter of $15 \mu \mathrm{m}$. The collimation and the focusing length are 160 and $200 \mathrm{~mm}$, respectively. A focus diameter of approx. $25 \mu \mathrm{m}$ has been measured using a Primes HighPower-MicroSpotMonitor

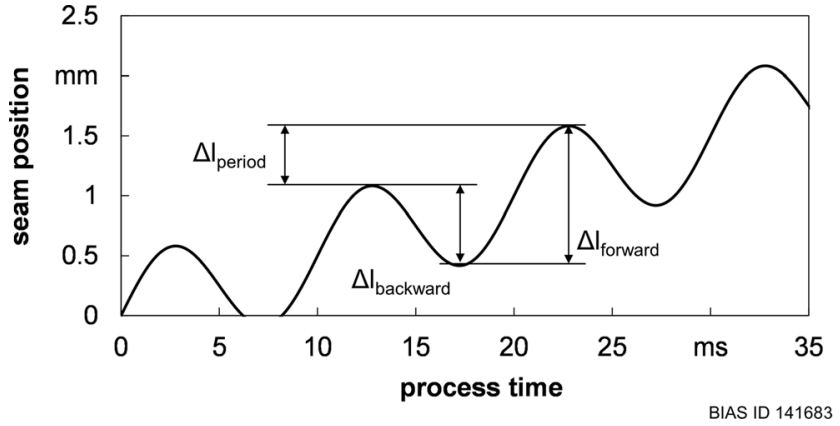

Fig. 3 Resulting laser path for an exemplary sinusoidal beam oscillation with an oscillation width of $0.9 \mathrm{~mm}$ and an oscillation frequency of $100 \mathrm{~Hz}$ at a welding speed of $50 \mathrm{~mm} / \mathrm{s}$
[23]. The process zone is shielded against the surrounding atmosphere by an argon gas flow.

\subsubsection{High-speed imaging}

A high-speed camera (Phantom v5.1, Vision Research) being equipped with an 8-bit complementary metal-oxide-semiconductor sensor (CMOS sensor) with $1024 \times 1024$ pixels has been installed in combination with an additional illumination diode laser having a wave length of $810 \mathrm{~nm}$ and an output power of $500 \mathrm{~W}$ (Cavilux HF, Cavitar) in order to observe the weld pool behavior during the process. A macro lens has been mounted in order to zoom in on the process zone. The maximum resolution can be used up to a frame rate of $1200 \mathrm{~Hz}$. The complete experimental setup consists of the laser head, the high-speed camera, the illumination laser, and the clamping system; see Fig. 4.

\subsection{Methods}

\subsubsection{Metallographic analysis}

The extent of pore formation is evaluated by longitudinal (parallel to welding direction=y-direction) micro-sections in the weld center (microscope Axio Imager A1m, Zeiss). Longitudinal sections enable a more meaningful determination of the seam porosity than cross-sections because a significant larger part of the seam is taken into account. Cross-sections show only the porosity of a single seam position. For example, the seam surface shown in Fig. $1 \mathrm{~b}$ and the longitudinal section in Fig. 5 demonstrate that cross-sections of different seam positions would probably show completely different porosity values.

The prepared longitudinal sections are analyzed along a seam distance of $20 \mathrm{~mm}$. The grayscale micrograph of each section is transferred into a black-and-white picture enabling an automatic measurement of the seam area $A_{\text {seam }}$ (white area)

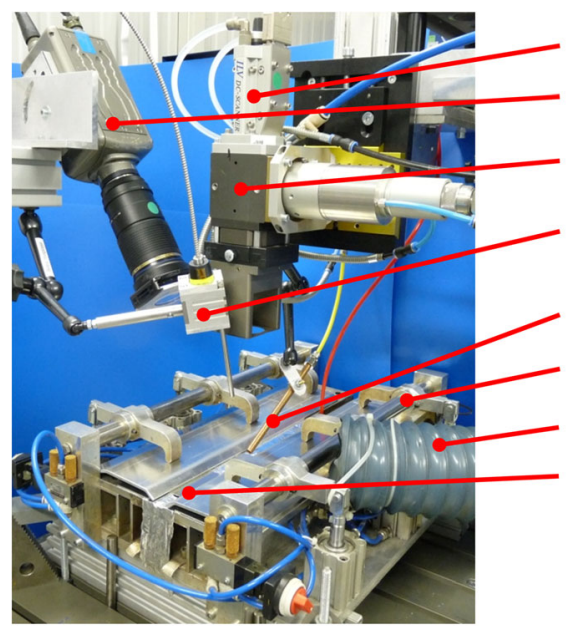

scanner system high speed camera laser head illumination laser for high speed imaging shielding gas nozzle clamping device fume extractor specimen 


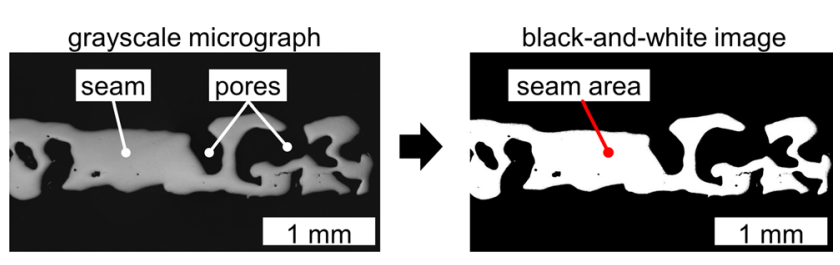

center porosity $=\frac{A_{\text {reference }}-A_{\text {seam }}}{A_{\text {reference }}}$

$\mathrm{A}_{\text {seam }} \quad$ seam area (white area)

$A_{\text {reference }}$ averaged seam area of five pore-free reference specimens BIAS ID 141678

Fig. 5 Methodology for the determination of the center porosity of a seam

using the MATLAB software by counting the white and black pixels. The number of white pixels is converted into the seam area. One pixel corresponds to $1.9 \mu^{2}$ due to the optical system of the microscope enabling the detection of pores in this scale. The procedure for the determination of the center porosity is illustrated in Fig. 5 showing a part of an exemplary longitudinal micro-section. In order to evaluate the porosity of the seams welded with polymeric interlayers, five pore-free specimens welded without any contaminations are also analyzed that way as reference. As indicator for the extent of pore formation, the value of center porosity is defined and determined according to Eq. 7 given in Fig. 5. The center porosity of a specimen is calculated by dividing the difference between the reference area $A_{\text {reference }}$ (averaged seam area of pore-free specimens) and the seam area of the specimen $A_{\text {seam }}$ by the reference area $A_{\text {reference }}$. Thus, this center porosity value does not directly represent pore sizes but indirectly the porosity by the missing seam material displaced from the seam center due to closed and open pores as well as melt bulges and spatter ejections. In case of differences in the range of only a few percentages between two specimens, it has to be noted that excess weld metal and sagging of the weld surface or the root and gap sizes can potentially also affect the determined value of center porosity. Longitudinal sections being misaligned to the weld center due to failures in the preparation processes are not considered in the analysis.

In addition, exemplary cross-sectional micrographs are extracted from several seams to measure seam width values at the positions of the gaps within the three-sheet joints in order to evaluate the heat input.

\subsection{Program}

In this paper, bead-on-plate welding experiments are analyzed. The welds were carried out using a laser output power of $500 \mathrm{~W}$. The welding speed is given by the movement of the specimen mounted on an $x$-y-table. The welding speed is $50 \mathrm{~mm} / \mathrm{s}$. The focal plane of the laser beam is positioned on the surface of the top sheet. Seams, welded with oscillation widths of 0.5 and $0.9 \mathrm{~mm}$ and oscillation frequencies of 100 , 150 , and $400 \mathrm{~Hz}$, are discussed and compared to seams
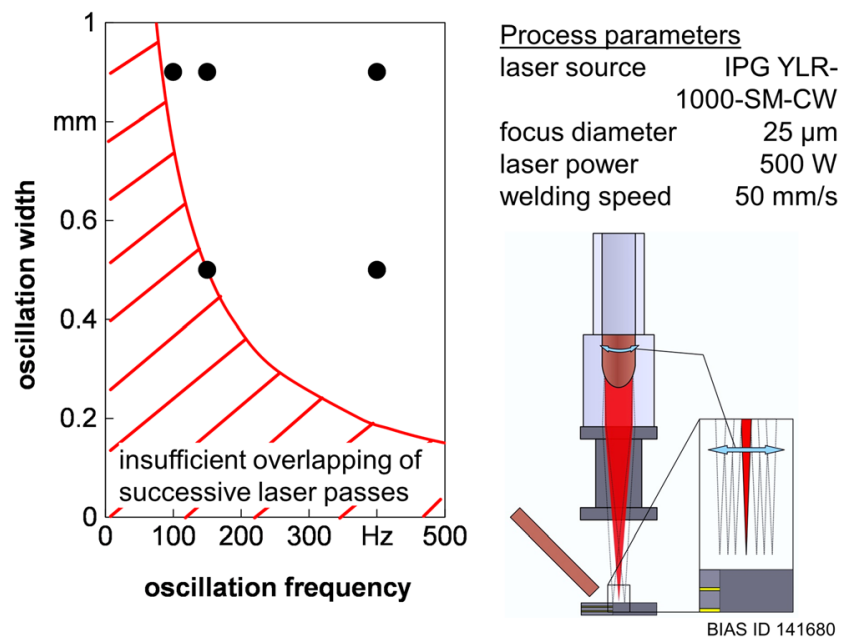

Fig. 6 Diagram showing the investigated parameter combinations of oscillation width and oscillation frequency and the range of non-suitable parameter combinations

welded by a standard single-pass process without oscillating laser beam. Three specimens have been welded at each parameter set displayed in Fig. 6. The combinations of oscillation width and oscillation frequency according to the red hatched area in Fig. 6 do not result in the wanted overlapping of at least two successive laser passes at each seam position along the seam length (see Eq. 6), because the resulting laser speed is not at least three times faster than the welding speed.

As reference for the calculation of the center porosity values, an averaged seam area is derived from welding experiments of five specimens without polymeric interlayers. Furthermore, in order to investigate the melt pool behavior depending on the oscillation parameters without influences of evaporating contaminations, additional experiments are carried out using specimens without polymeric interlayers for selected parameter sets.

\section{Results}

\subsection{Analysis of longitudinal sections}

Longitudinal sections have been made for all welded specimens as described beforehand. The averaged seam area of the five reference seams welded without any polymeric interlayers is measured to $16.5 \pm 0.7 \mathrm{~mm}^{2}$. The standard deviation of $0.7 \mathrm{~mm}^{2}$ represents $4 \%$ of the mean value. The reference seams show, as required, almost no pores or other seam defects. Exemplarily, the longitudinal section of a reference seam is presented in Fig. 7. The associated surface of this

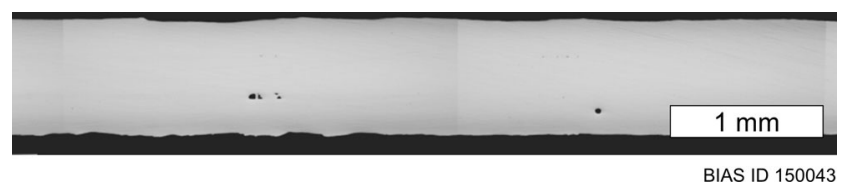

Fig. 7 Exemplary longitudinal section of a reference seam belonging to the seam surface in Fig. 1a 


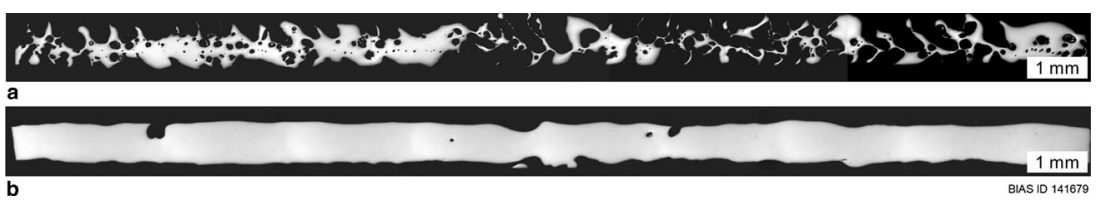

Fig. 8 Longitudinal sections of two three-sheet joints having polymeric interlayers belonging to the seams shown in Fig. 1b and c: (a) standard single-pass welding; (b) double-pass welding

seam has been shown beforehand in Fig. 1a. In the following, the value of $16.5 \mathrm{~mm}^{2}$ is used as reference area in the calculation of the center porosity values.

In addition, longitudinal sections of the further two seams whose seam surfaces have been already displayed in Fig. 1b, c are prepared; see in Fig. 8. The center porosity of the seam in Fig. 8a, which belongs to the three-sheet joint having two polymeric interlayers and being welded by the standard single-pass process without oscillation, is calculated to $63 \%$. The section demonstrates a high porosity along the analyzed seam length. Besides closed pores, mainly, open porosity and melt bulges can be seen. As described above, a value of $63 \%$ does not mean that $63 \%$ of the overall seam material is ejected by the process. The value implies that $63 \%$ of the seam material is missing in the longitudinal (parallel to welding direction $=y$-direction) micro-section of the weld seam center. The material is displaced by pores or bulges and only partly ejected by spatters. In contrast to this standard weld, the longitudinal section of the specimen being double-pass welded features a center porosity of $9 \%$; see Fig. $8 \mathrm{~b}$. The second welding pass was carried out after a cooling time of $5 \mathrm{~min}$. The open and closed porosity has extremely decreased due to the re-welding. Thus, the analysis of the longitudinal micro-sections confirms the aforementioned statement that the second pass significantly decreases porosity.

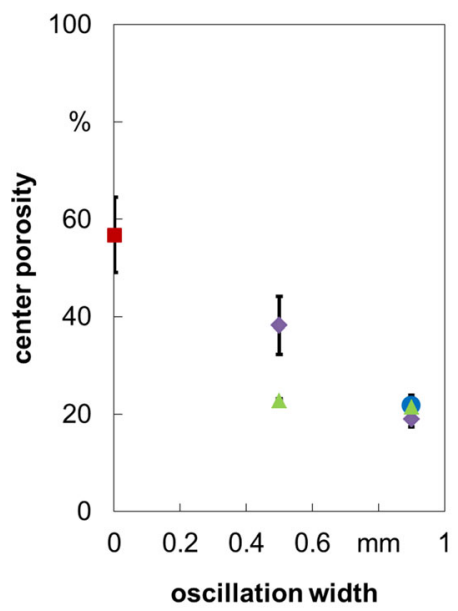

Oscillation frequencies

- without oscillation

$\checkmark 400 \mathrm{~Hz}$

$\triangle 150 \mathrm{~Hz}$

- $100 \mathrm{~Hz}$

Process parameters laser source IPG YLR1000-SM-CW collimation length $160 \mathrm{~mm}$ focusing length $200 \mathrm{~mm}$ focus diameter $\quad 25 \mu \mathrm{m}$ laser power $\quad 500 \mathrm{~W}$ welding speed $50 \mathrm{~mm} / \mathrm{s}$ scanner system ILV DC scan direction longitudinal base material steel 1.4301 contaminations polymeric

BIAS ID 141681

Fig. 9 Determined values of center porosity with respect to the oscillation width
The determined values of center porosity with respect to the oscillation width are shown in Fig. 9. The mean values and standard deviations stand for three specimens of each parameter set. In the case of welding without beam oscillation, just two longitudinal sections are averaged due to a failure of the section position of the third specimen. The diagram demonstrates that all welded seams with beam oscillation have lower values of center porosity in the longitudinal sections than the seams welded without oscillating laser beam having an averaged center porosity of $57 \pm 8 \%$. In case of the oscillation frequency of $400 \mathrm{~Hz}$ the averaged center porosity decreases with an increased oscillation width from this value to $38 \pm 6 \%$ at a width of $0.5 \mathrm{~mm}$ and further to $19 \pm 2 \%$ at a width of $0.9 \mathrm{~mm}$. In case of the lower frequency of $150 \mathrm{~Hz}$, the averaged center porosity values are among the lowest in the test set nearly independent from the oscillation width. The values are $23 \pm$ $1 \%$ at a width of $0.5 \mathrm{~mm}$ and $21 \pm 2 \%$ at a width of $0.9 \mathrm{~mm}$. The additional tests with an oscillation frequency of $100 \mathrm{~Hz}$ and an oscillation width of $0.9 \mathrm{~mm}$ result in the averaged center porosity of $22 \pm 1 \%$ which is comparable to the results found at the other observed frequencies at the same oscillation width.

The longitudinal section of an exemplary seam welded with an oscillation frequency of $400 \mathrm{~Hz}$ and an oscillation width of $0.9 \mathrm{~mm}$ having a center porosity of $24 \%$ is presented in Fig. 10. It is shown that the porosity in the seam is decreased in comparison to seams welded by a standard single-pass process without oscillation (compare Fig. 8a). However, some open and closed pores as well as partially reduced seam height are detectable.

\subsection{Analysis of cross-sections}

The seam width indicates the heat input being responsible for the amount of evaporated contamination material. Thus, cross-sectional micrographs have been prepared in order to measure the seam width at the positions of the two gaps within the three-sheet joints, as shown in Fig. 11. The values of both gaps $s_{\text {gap }, 1}$ and $s_{\text {gap }, 2}$ as well as their average $s_{\text {gap,average }}$ have been determined exemplarily for one cross-section of each parameter set, see Table 2.

The standard single-pass welding process results in an averaged seam width of $0.22 \mathrm{~mm}$ at the positions of the gaps. 


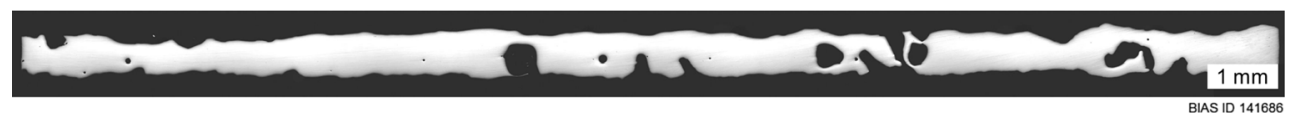

Fig. 10 Longitudinal section of the seam of a three-sheet specimen having polymeric interlayers welded with beam oscillation (oscillation frequency of $400 \mathrm{~Hz}$, oscillation width of $0.9 \mathrm{~mm}$ )

The further measured values show that welding with beam oscillation tends to increase the seam width. However, the measured averaged values of both gaps vary from 0.21 to $0.27 \mathrm{~mm}$. The maximum seam width is measured for $400 \mathrm{~Hz}$ oscillation frequency and $0.5 \mathrm{~mm}$ oscillation width.

\subsection{Melt pool analysis}

For a more detailed investigation of the welding processes belonging to the aforementioned different center porosity values, additional joints have been welded having no polymeric interlayers to avoid any additional influences on the melt pool behavior at this point. Besides the standard single-pass welding the process behavior for three selected oscillation parameter sets are analyzed by high-speed imaging. The

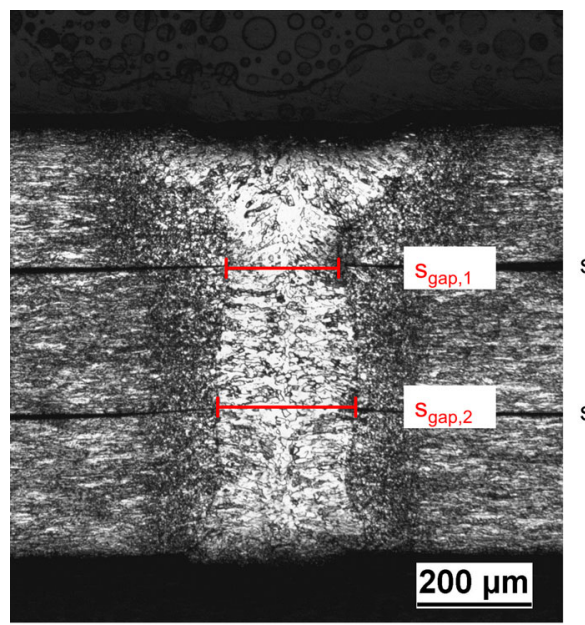

$\mathrm{S}_{\mathrm{gap}, 1}$ : seam width at the position of the first gap

$\mathrm{S}_{\mathrm{gap}, 2}:$ seam width at the position of the second gap

BIAS ID 150042

Fig. 11 Exemplary cross-sectional micrograph of a seam welded by the standard single-pass process in case of a specimen without polymeric interlayers (equal to Fig. 1e) melt pool length values are measured according to the snapshots in Fig. 12.

The melt pool length is $0.64 \mathrm{~mm}$ when welding without oscillation. Consequently, the melt pool is approximately three times longer than it is wide considering the beforehand measured seam width. It features the typical drop shape. Using beam oscillation increases the melt pool length significantly to 1.36 and $1.60 \mathrm{~mm}$ in case of an oscillation frequency of $400 \mathrm{~Hz}$ and oscillation widths of 0.5 and $0.9 \mathrm{~mm}$, respectively. The welding with a lower oscillation frequency of $100 \mathrm{~Hz}$ and an oscillation width of $0.9 \mathrm{~mm}$ results in a melt pool length of $1.68 \mathrm{~mm}$. The melt pool at $400 \mathrm{~Hz}$ has an elliptical shape and remains nearly constant over time. In contrast at $100 \mathrm{~Hz}$, it has been observed that a smaller melt pool tip runs out of the melt pool surrounding the oscillating laser beam. This part of the melt pool solidified when the laser moves back in the main melt pool. Such kind of partial solidification and re-melting has also been observed at the rear of the seam between two laser passes.

In order to illustrate how seam defects are re-passed by the laser beam due to the oscillation, Fig. 13 shows snapshots of the welding process of a specimen with polymeric interlayers. The first image row shows an ejection of melt. As a result, spatters occur. The following images show the following oscillation period when the seam position featuring the seam defect is passed again by the laser beam.

\section{Discussion}

The experiments reported in this paper show that usage of beam oscillation can significantly decrease the porosity of multiple-sheet weld seams having polymeric contaminations as interlayers. In contrast, Berend et al. reported that an

Table 2 Measured seam width of an exemplary cross-section of each investigated parameter set

\begin{tabular}{|c|c|c|c|c|c|c|c|}
\hline Welding mode & Unit & $\begin{array}{l}\text { Without oscillation } \\
\text { (standard single- } \\
\text { pass welding) }\end{array}$ & With oscillation & With oscillation & With oscillation & With oscillation & With oscillation \\
\hline Oscillation frequency & $\mathrm{Hz}$ & 0 & 400 & 400 & 100 & 150 & 150 \\
\hline Oscillation width & $\mathrm{mm}$ & 0 & 0.5 & 0.9 & 0.9 & 0.5 & 0.9 \\
\hline$s_{\text {gap }, 1}$ & $\mathrm{~mm}$ & 0.20 & 0.28 & 0.22 & 0.26 & 0.23 & 0.27 \\
\hline$s_{\text {gap }, 2}$ & $\mathrm{~mm}$ & 0.24 & 0.26 & 0.21 & 0.23 & 0.19 & 0.23 \\
\hline$s_{\text {gap,average }}$ & $\mathrm{mm}$ & 0.22 & 0.27 & 0.215 & 0.245 & 0.21 & 0.25 \\
\hline
\end{tabular}


Welding mode and melt pool shape (welding experiments without any polymeric contaminations)

Center porosity (welding experiments with polymeric interlayers)

a without oscillation

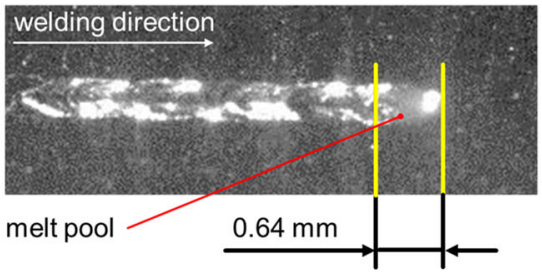

$57 \% \pm 8 \%$

b $400 \mathrm{~Hz}$ oscillation frequency

$0.5 \mathrm{~mm}$ oscillation width

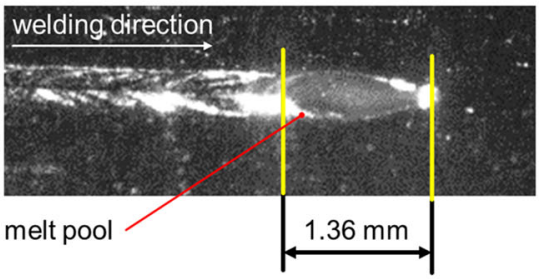

$38 \% \pm 6 \%$

C $400 \mathrm{~Hz}$ oscillation frequency $0.9 \mathrm{~mm}$ oscillation width

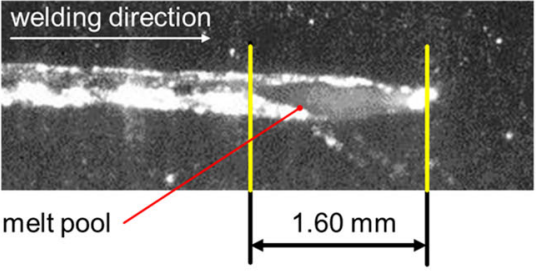

$19 \% \pm 2 \%$

d $100 \mathrm{~Hz}$ oscillation frequency $0.9 \mathrm{~mm}$ oscillation width

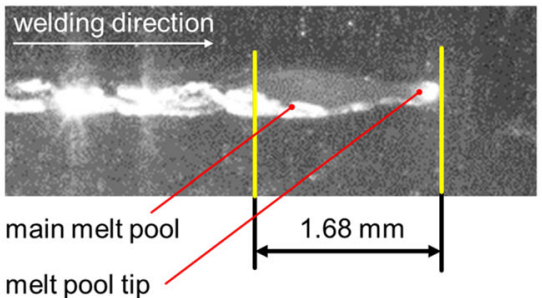

$22 \% \pm 1 \%$

BIAS ID 141684

Fig. 12 Comparison of the melt pool behavior during standard single-pass welding (a) with melt pool shapes during welding with oscillating laser beam for three selected oscillation parameters (b-d) in case of welding polymer-free specimens

influence of longitudinal beam oscillation on the pore formation in welding of zinc-coated steel sheets was not observed [17]. A decreasing porosity was only measured in aluminum welding for oscillation frequencies of 1000 and $1500 \mathrm{~Hz}$. The differences between the investigations might be caused by different ratios of keyhole size and oscillation width. Berend et al. used a beam with a ten times larger focus diameter at comparable oscillation widths. Thus, the ratio of keyhole size to oscillation width is about ten times lower than in the experiments reported in this paper. The focus of the experiments by Berend et al. was to affect the keyhole shape while the aim in this investigation was to affect the melt pool shape. Although, influencing the keyhole is not the main goal of this work, it has to be noted that the keyhole diameter and shape might also be influenced due to varied laser speeds [24] depending on the oscillation frequency and oscillation width. The effective laser speed is increased depending on the oscillation parameters up to $720 \mathrm{~mm} / \mathrm{s}$ averaged over time. In consequence, the overall heat input is affected by the oscillation parameters because the absorption and in case of full penetration the transmission of laser energy through the keyhole vary with respect to the parameter set. This can explain the different melt pool dimensions, shown in the experiments of this paper, in spite of the fact that the energy input per unit length (laser output power/ welding speed) was kept constant.

In this paper, the defined parameter of center porosity acts as indicator for the quality of an existing seam. The center porosity has been more than halved from $57 \pm 8 \%$ for standard seams welded without oscillating beam to approximately $20 \%$ when using longitudinal beam oscillation parallel to the welding direction. The averaged center porosity of all experiments with oscillating beam are nearly $20 \%$ excluding the seams welded with an oscillation frequency and width of $400 \mathrm{~Hz}$ and $0.5 \mathrm{~mm}$ which have a significant higher center porosity of $38 \pm 6 \%$.

As reason for this significant decrease of porosity by using beam oscillation, the lengthening of the melt pool is identified because the time for degassing of the evaporated contamination material increases simultaneously with the melt pool length. It has been demonstrated that a longer oscillation width results in a longer melt pool which causes the low values of center porosity at the oscillation width of $0.9 \mathrm{~mm}$ while, partly, higher porosity values were measured in case of $0.5 \mathrm{~mm}$. However, the benefit of a longer degassing time would be canceled out when the amount of vapor entering and being captured in the melt pool increases similarly. Assuming that the amount of vapor depends mainly on the melt pool width, the melt pool length has to be increased significantly more than the melt pool width increases in order to reduce porosity. Consequently, the melt pool shape has to be changed. The measured melt pool length and seam width show that in case of $0.9 \mathrm{~mm}$ oscillation width, the melt pool is lengthened by approx. $150 \%$ in comparison to standard single-pass welding while the measured averaged seam width at the gap positions is increased less than $15 \%$. This relation can probably also explain the higher center porosity of $38 \pm 6 \%$ in case of the oscillation parameters of $400 \mathrm{~Hz}$ and $0.5 \mathrm{~mm}$ in contrast to $23 \pm 1 \%$ when oscillating with $150 \mathrm{~Hz}$ at the same oscillation width. The 
Fig. 13 Visualization of in-process re-passing of a seam position featuring a seam defect by the oscillating laser beam $(150 \mathrm{~Hz}$ oscillation frequency, $0.9 \mathrm{~mm}$ oscillation width)
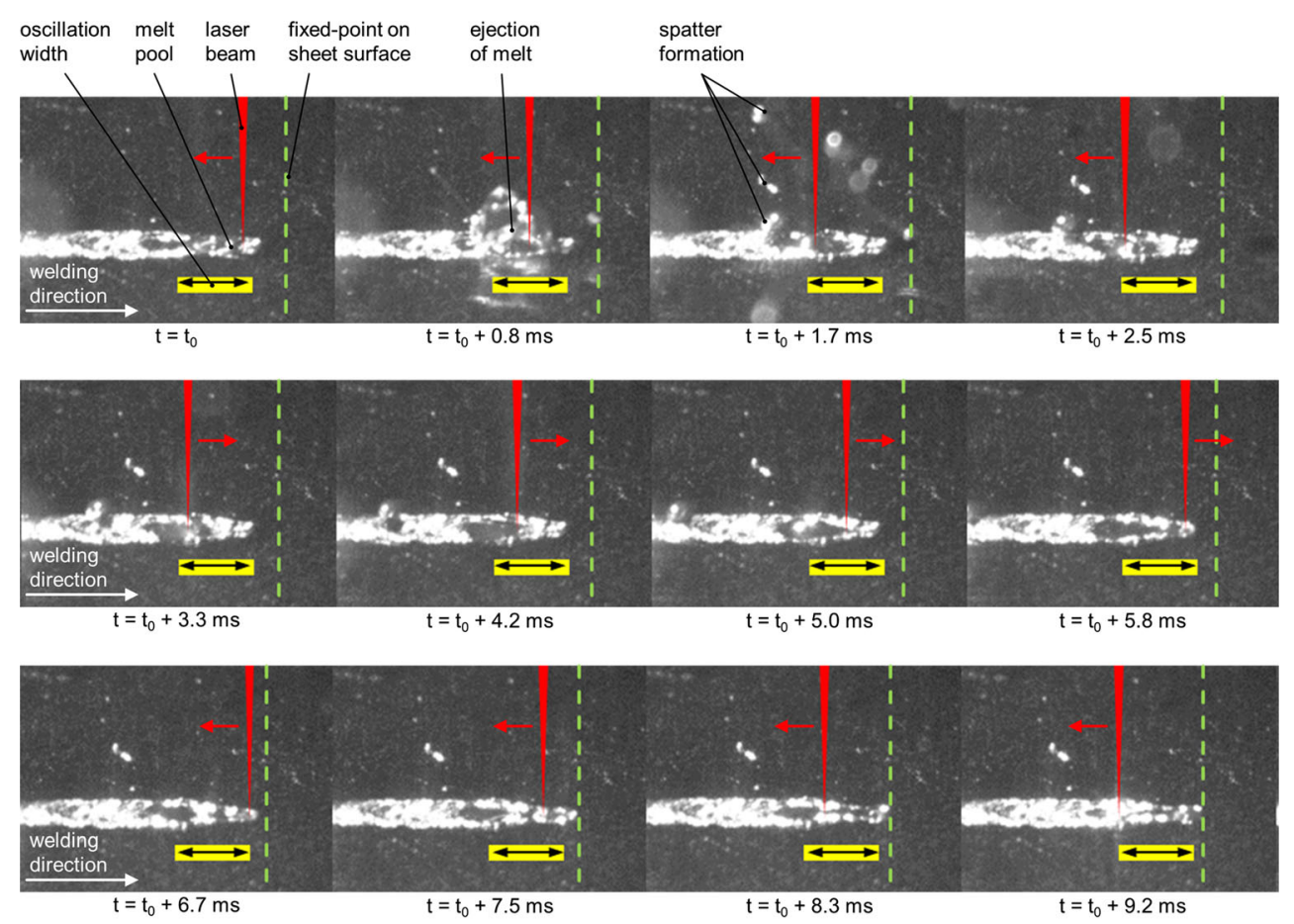

BIAS ID 141685 exemplary measured seam in case of $400 \mathrm{~Hz}$ oscillation frequency is significantly wider than the seam at $150 \mathrm{~Hz}$ with $0.27 \mathrm{~mm}$ in comparison to $0.21 \mathrm{~mm}$. Using beam oscillation, the lowest center porosity of $19 \pm 2 \%$ was measured for an oscillation frequency of $400 \mathrm{~Hz}$ and an oscillation width of $0.9 \mathrm{~mm}$. The resulted melt pool length was $1.6 \mathrm{~mm}$ which implies a maximum degassing time of $32 \mathrm{~ms}$ considering the welding speed of $50 \mathrm{~mm} / \mathrm{s}$.

Overall, the results indicate that the center porosity tends to increase with increasing seam width and decreasing melt pool length, respectively. Exemplarily, the averaged center porosity

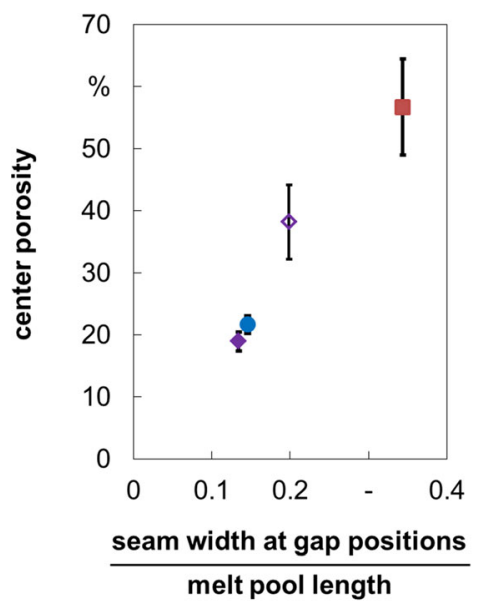

Oscillation frequencies and widths

- without oscillation

$\diamond 400 \mathrm{~Hz} ; 0.5 \mathrm{~mm}$

- $100 \mathrm{~Hz} ; 0.9 \mathrm{~mm}$

$400 \mathrm{~Hz} ; 0.9 \mathrm{~mm}$

Process parameters laser source IPG YLR1000-SM-CW focus diameter $\quad 25 \mu \mathrm{m}$ laser power $\quad 500 \mathrm{~W}$ welding speed $50 \mathrm{~mm} / \mathrm{s}$ scanner system ILV DC scan direction longitudinal base material steel 1.4301 contaminations polymeric BIAS ID 150044

Fig. 14 Center porosity as a function of the ratio of seam width and melt pool length calculated by the measured values given in Fig. 9 and Table 2 is plotted against the ratio of seam width and melt pool length in Fig. 14 calculated by the measured values given in Fig. 9 and Table 2 .

\section{Conclusions}

The use of in-process longitudinal beam oscillation parallel to the welding direction can significantly decrease pore formation in deep-penetration laser welding of multiple-sheet specimens having extensive polymeric contaminations without decreasing welding speed. The center porosity, measured in longitudinal sections as indicator for the seam porosity, has been reduced from more than 50 to $20 \%$ by applying beam oscillation. The decrease of remaining porosity is caused by increasing the degassing time depending on the oscillation parameters due to a lengthening of the melt pool. However, it is important to avoid or minimize a simultaneous increase of the seam width because, consequently, the amount of evaporated contamination material would increase similarly. The experiments have demonstrated that the melt pool shape changes from the typical drop shape to a flat elliptical shape using beam oscillation with an oscillation width of $0.9 \mathrm{~mm}$. In doing so, the maximum decrease of porosity has been achieved when oscillating with a frequency of $400 \mathrm{~Hz}$. The melt pool was lengthened by $150 \%$ from $0.64 \mathrm{~mm}$ at standard single-pass welding to $1.6 \mathrm{~mm}$ which implies an additional degassing time of $19 \mathrm{~ms}$ considering the welding speed of $50 \mathrm{~mm} / \mathrm{s}$. In 
conclusion, the potential of this technique for welding contaminated multiple-sheet joints has been proven.

Acknowledgments The authors gratefully acknowledge financial support of this work by DFG (FOR1224). The authors also thank their alumnus Vitalij Wottschel (today LaserMicronics $\mathrm{GmbH}$ ) for the support and their partners within the research group "Schwarz-Silber" FIBRE (Faserinstitut Bremen e.V.), IFAM (Fraunhofer-Institut für Fertigungstechnik und angewandte Materialforschung), BIME (Bremer Institut für Strukturmechanik und Produktionsanlagen), IWT (Stiftung Institut für Werkstofftechnik), and, especially, Anna Lang (FIBRE) for the cooperation and the support at specimen manufacturing.

Author details Dipl.-Ing. Peer Woizeschke, leader of the group joining technology, and Prof. Dr.-Ing. Frank Vollertsen, director, are with the BIAS - Bremer Institut für angewandte Strahltechnik $\mathrm{GmbH}$, Bremen, Germany. Prof. Dr.-Ing. Frank Vollertsen is professor at the University of Bremen. Eugen Mosgowoi is student in the degree program of production engineering.

The "BIAS ID" numbers are part of the figures and allow the retraceability of the results with respect to mandatory documentation required by the funding organization.

Open Access This article is distributed under the terms of the Creative Commons Attribution 4.0 International License (http:// creativecommons.org/licenses/by/4.0/), which permits unrestricted use, distribution, and reproduction in any medium, provided you give appropriate credit to the original author(s) and the source, provide a link to the Creative Commons license, and indicate if changes were made.

\section{References}

1. Bley H, Weyand L, Luft A (2007) An alternative approach for the cost-efficient laser welding of zinc-coated sheet metal. CIRP Ann Manuf Technol 56(1):17-20

2. Bastick A, Griebel M, Bergmann JP, Patschger A (2010) Anwendungsbezogene Vorteilsanalyse des Laserstrahlschweißens mit starker Fokussierung. 7. Laseranwenderforum (LAF'10), eds.: F. Vollertsen, T. Seefeld. BIAS-Verlag Bremen, (40):11-24

3. Bergmann JP, Patschger A, Hild M (2008) Grundlegende Untersuchungen zur Prozessauslegung beim Schweißen mit Lasern höherer Brillanz. 6. Laseranwenderforum (LAF'08), eds.: F. Vollertsen, T. Seefeld. BIAS-Verlag Bremen, 36:157-64

4. Sovetchenko P (2007) Herstellung beschichteter Mehrblechverbindungen im Karosseriebau mit Hilfe der Hochleistungslasertechnik. Shaker, Aachen

5. Milberg J, Trautmann A (2009) Defect-free joining of zinc-coated steels by bifocal hybrid laser welding. Prod Eng Res Devel 3(1):9-15

6. Quiet Steel | Material Sciences Corporation. [June 26, 2014]; Available from: http://www.matsci.com/acoustic-materials/quietsteel/

7. Woizeschke P, Wottschel V (2013) Recent developments for laser beam joining of CFRP-aluminum structures. Materials Science
Engineering, Symposium B6 - Hybrid Structures, Procedia Materials Science 2(0):250-8

8. Geiger M, Kägeler C, Schmidt M (2008) High-power laser welding of contaminated steel sheets. Prod Eng Res Devel 2(3):235-40

9. Pan Y, Richardson IM (2011) Keyhole behaviour during laser welding of zinc-coated steel. J Phys D Appl Phys 44(4):45502

10. Geiger M, Leitz K, Koch H, Otto A (2009) A 3D transient model of keyhole and melt pool dynamics in laser beam welding applied to the joining of zinc coated sheets. Prod Eng Res Devel 3(2):127-36

11. Fabbro R, Coste F, Goebels D, Kielwasser M (2006) Study of CW Nd-Yag laser welding of Zn-coated steel sheets. J Phys D Appl Phys 39(2):401

12. Yih-fong $\mathrm{T}$ (2006) Gap-free lap welding of zinc-coated steel using pulsed CO2 laser. Int J Adv Manuf Technol 29(3-4):287-295

13. Schmidt M, Kägeler C (2008) Prozessuntersuchung zum Laserstrahlschweißen verzinkter Karosseriebleche. 6. Laseranwenderforum (LAF'08), eds.: F. Vollertsen, T. Seefeld. BIAS-Verlag Bremen, (36):173-88

14. Chen W, Ackerson P, Molian P (2009) CO2 laser welding of galvanized steel sheets using vent holes. Mater Des 30(2):245-51

15. Yang S, Carlson B, Kovacevic R (2011) Laser welding of highstrength galvanized steels in a gap-free lap joint configuration under different shielding conditions. Welding J, 90(1)

16. Xie J (2002) Dual beam laser welding. Weld J 81(10):223s-230s

17. Berend O, Haferkamp H, Meier O, Engelbrecht L. High-frequency beam oscillating to increase the process stability during laser welding with high melt pool dynamics. Laser Institute of America, editor. Proceedings of the 24th International Congress on Applications of Lasers \& Electro-Optics, Orlando: LIA Pub;: 10321041

18. Akhter R, Steen WM, Watkins KG (1991) Welding zinc coated steel with a laser and the properties of the Weldment. J Laser Appl 3(2):9-20

19. Gu H, Shulkin B (2011) A practical use of humping effect in laser beam welding. J Laser Appl, 23(1):-

20. Colombo D, Previtali B (2014) Laser dimpling and remote welding of zinc-coated steels for automotive applications. Int J Adv Manuf Technol 72(5-8):653-663

21. Ma J, Kong F, Carlson B, Kovacevic R (2013) Two-pass laser welding of galvanized high-strength dual-phase steel for a zero-gap lap joint configuration. J Mater Process Technol 213(3):495-507

22. Kiuna N, Lawrence C, Fontana Q, Lee P, Selerland T, Spelt P (2002) A model for resin viscosity during cure in the resin transfer moulding process. Compos A: Appl Sci Manuf 33(11):1497-503

23. Märten O, Wolf S, Kramer R, Schwede H, Brandl V (2008) Strahleigenschaften von Strahlquellen und Laseranlagen mit brillanten fasergekoppelten Multikilowatt-Festkörperlasern. 6 . Laseranwenderforum (LAF'08), eds.: F. Vollertsen, T. Seefeld. BIAS-Verlag Bremen, (36):147-56

24. Kawahito Y, Matsumoto N, Abe Y, Katayama S (2011) Relationship of laser absorption to keyhole behavior in high power fiber laser welding of stainless steel and aluminum alloy. J Mater Process Technol 211(10):1563-8

25. Aalco Metals Ltd. Data sheet-Stainless Steel 1.4301 Sheet and Plate; 2014. [January 24, 2014] 